\title{
Anti-Glare Headlamp a Safe Option for Better Vision to the Rider
}

\author{
Shrinivas S. Metan, Abhishek R. Kshirsagar, Govind N. Samleti, Vinayak K Patki
}

\begin{abstract}
As per the Ministry of Road Transport and Highways report 2018, every day around 410 road fatalities in India, which is one of the highest road crash fatalities in the world. Evaluations show that an average of $1 \%$ of nighttime fatal crash lists glare as a major contributor factor. On the multilane highway, vehicle with high glared headlamp light disturbs the approaching motorist eyes due to which the vision of the motorist gets indistinct for a few seconds causing accidents on the road.

In the present work, a novel concept of an anti-glare headlamp is proposed to avoid the temporary blindness of the motorist due to momentary high glares from approaching vehicles. The antiglare film reduces glare and halos around headlamp light at night and eliminates unattractive reflections on the eyes. A successful attempt is made to analyze the visibility of objects in a scene by inspecting contrast reduction caused by the illuminance contribution. Our visualization of scenes with the cover-up veiling illuminance gives a good indication of the visual problems that might occur, but the images are not exactly what people perceive when observing the scene in reality.

In the present study, after number of samples, it has found that that the mixture of yellow and green color film combination on halogen bulb headlamp will give a good vision to the rider as well as glare-free effect to the approaching motorist. Visualizations with the proposed method can still improve the understanding of human vision so that visual aspects can be taken into account in design and quality assurance of head lamp.

Index Terms-Headlamp, Motorist, Glare, Visibility
\end{abstract}

\section{INTRODUCTION}

Headlamp is a device which is attached in front of the vehicle when it is turned on, the motorist can see the road, pedestrians, road signs, symbols and other vehicles at night. Headlamp should give maximum visibility to motorist and minimum glare to the approaching motorist while driving a vehicle. The headlamp is having two beams high beam and low beam which can be used effectively during night drive.

Effective visibility is an important element while driving the vehicle at night. Development in the analysis of the visual elements of safe driving environments may be of great benefit to society. Visual disability appears to be one of the major factors related to traffic accidents [01]. Discomfort glare is defined as annoying or even painful sensations that can be elicited from a bright source of lightening the field of view. It is distinguished from disability glare which is defined as the reduction in visibility that a bright light causes, through scattered light in the eye that reduces the apparent illuminance contrast of objects in

\footnotetext{
Revised Manuscript Received on July 18, 2019.

Dr.Shrinivas S. Metan, Nagesh Karagji Orchid College of Engineering and Technology, Solapur (shrinims@gmail.com)

Abhishek R. Kshirsagar, Nagesh Karagji Orchid College of Engineering and Technology, Solapur (kshirsagar8983@gmail.com)

Govind N. Samleti, Punyashlok Ahilyadevi Holkar Solapur University (govindsamleti08@gmail.com)

Dr.Vinayak K Patki, Nagesh Karagji Orchid College of Engineering and Technology, Solapur (vinayakpatki@ orchidengg.ac.in)
}

the field of view [02]. Glare is more critical on two-lane than on multi-lane highways because generally lower light levels on two-lane highways increase the effect of scattered light in the eye due to less separation because two-lane have roads have less likely to have a marking that improves lane keeping.

The companies which provide the glare-free headlamp in the market are Volvo-Anti dazzle headlamps, Ford-Glare free high beam, and Mercedes-Adaptive high beam assistant, which include cameras, sensors and light control module. To fit these types of glare-free headlamps in a vehicle the cost is approximately 250\$ [03]. Recent developments in adaptive lightning have addressed some of the dangerous situation due to headlamp glare and limitations of standard headlights used during the night ride. However, they have limited flexibility. Their solution to glare is switching between high and low beams, turning of beams towards the opposing lane or rotating the beam as the vehicle turns. But these are not designed for all driving environments and these sudden changes can create a distraction for the motorist. To fix the above problem AntiGlare headlamp plays a vital role with the help of transparent colored vinyl films which is the most costeffective method rather than the other methods which are available in the market.

\section{THE SIGNIFICANCE OF RESEARCH WORK}

You hate it when the motorist in the opposite lane blinds you with high beam, or when the glare from the vehicle behind keeps you for looking in the rearview mirror, a solution might be adjusted around the corner.

The goals of Automotive Engineers, designers and researchers are to improve driving experience and safety. The anti-glare headlamp enables the motorist to take maximum advantage of their high beams without the fear of blinding oncoming motorists with the glare that occurs while driving [04]. Even after 100 years of headlight development, almost half of vehicle accidents and deaths occur at night despite the fact that there is much less traffic then. Clear vision is essential, especially when you are driving at night. To reduces the effect of high beam that causes temporary vision blindness, due to reflection and halos of headlamps which virtually eliminated through Antiglare filmed headlights. 


\section{Problem Identification}

"New lights, Old problems". Motorists have been complaining about glare ever since electric headlights began replacing oil lamps on automobiles more than 100 years ago [04]. It hates when the motorist in the opposite lane blinds you with high beams. It is well known that the direct rays of light from automobile headlamps create a glare that blinds persons on road, especially motorists of forthcoming automobiles. Many benefits are being introduced from new headlight technology. Less power consumption and more visibility but with increased glare due to which there is a decrease in driver's awareness. The consumer's demands for more bright headlamps for better visibility have a direct link with the glare. Halogen bulb which is mostly used in the headlamp of the vehicle gives sufficient brightness and visibility to the driver but glare problem to other drivers. More glares are created by the halogen bulb as shown in Fig No. 1 which is more disturbing and annoying while driving the vehicle.

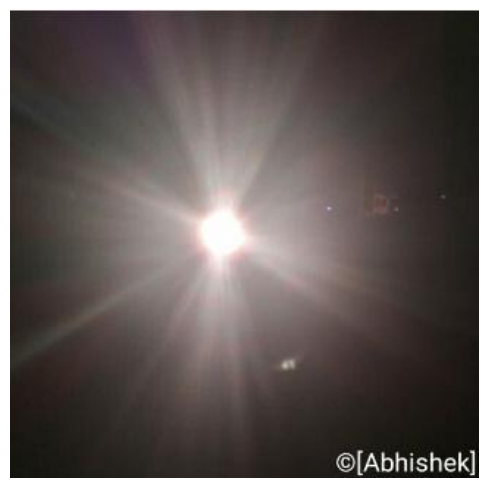

Fig No.1 Halogen bulb glare

In the present work the focus of research was to reduce the strain on eyes of motorist due to headlight by reducing the unwanted glare of headlight to have a safe drive at night.

\section{LITERATURE REVIEW}

New headlamp optical design is creating more glare scenarios on today's roadways. Evidence suggests that the spectral content of vehicle forward lightning may play a role in the glare that it produces [05].It has been proposed that the impact of glare illuminance, glare spectral power distribution, and glare source size. The impact of glare can be segregated into two areas: the reduction of visibility caused by scattered light in the eye (disability glare), and the sensations of discomfort caused by a glare source in the field of view (discomfort glare). With respect to disability glare, detection of peripheral targets worsened as the glare illuminance increased from 0.2 to 0.5 lux , detection of high reflectance targets (located $60 \mathrm{~m}$ ahead) was relatively unaffected by glare, targets very close to glare source and targets furthest from line of sight. With respect to discomfort glare, higher glare illuminance elicit subjective ratings of greater discomfort and was the most important determinant of discomfort spectral power distribution also affected discomfort. Glare source size had no impact on ratings of discomfort [06]. The minor vision can be influenced by many factors such as oncoming headlamp glare, fixed street lightning, and forward headlamp.
Oncoming headlamp sometimes cause disability glare that may vague motorist's vision, both favela and peripheral. Light sources with relatively more short-wavelength content are perceived as more glaring at the same specified intensity [07]. As per experiments were carried out to maintain the lane position most of the motorists use high beam headlight at night. When glare vehicle was used high beam headlamp participants on average underestimated their visual ability by $32 \%$ or $33 \%$ depending upon whether the participants were on high or low beam. These errors were on average smaller when the glare vehicle used low beam (an underestimated of $9 \%$ when passenger vehicle used low beam and an overestimate of 3\% when passenger used high beam). It has also been noticed that the glare from oncoming vehicles lean to overstress the point. The glare decreases the motorist's ability to see small high dissimilarity stimuli [08]. It has been reported that looking away from the roadway scene, or from rear view mirrors in the presence of glare, might also sensibly represent an increase in crash risk. Also the light which is brighter than the rest of one's field of view can also cause worry, irritation, or uneven pain and all this sensation is from the glare. When driving, glare can be caused by bright lights seen against a dark background, such as when headlamps of oncoming vehicles are seen in the field of view. Also they have researched that people experience more discomfort when exposed to blue color discharge headlamp than they are exposed to yellow color [09]. Experiment carried out their results shows that the halogen lamps produce more light by photoemission from a hot filament, as there is a gas in the bulb due to which the effectiveness and life of bulb get increase. Halogen lamps broadly used having typical color and temperature between 2800 and 3000 Kelvin degree and a natural spectral distribution [10]. The research shows that the halogen lamps are the ideal light source for spectrophotometer as they provide broadband spectral radiation from ultraviolet, through the visible and into infrared out of five microns [11]. The practical elimination of glare by beam control or variation of lamp intensity is a virtually impossible task. Clear vision is crucial, especially when you are driving at night. Anti-Glare lenses allows for faster recognition of potential hazards on the road. The reflection and halos of headlamps are virtually eliminated [12]. The driver's night vision is finite. Due to which there is risk of collision with pedestrians at night. The on-road test shows that the glare from headlamps of oncoming vehicles lowers the driver's ability to see pedestrians at night [13]. The studies found that even there is street lighting; glare creates a discomfort feeling to the driver. Dimming of the headlamp is possible to reduce the glare oncoming drivers, without prejudice the driving performance [14]. Increased beam pattern and more light output causes an incensement in glare of headlamp, which produce a discomfort equal to more illuminance[15].

\section{METHODOLOGY}

In the present work, different types of transparent vinyl color film shades on halogen headlamp, colors such as red, 
green, blue and yellow were used. The field experiment was held for continues five days. 150 participants from different age groups and genders were present while conducting the on-field experiment. A set of questionaries' were formed with the help of previous work done by the experts and then was given to the participants. A scooter that has a halogen bulb headlamp of $12 \mathrm{~V}$ is being used at a constant velocity of $45 \mathrm{Km} / \mathrm{hrs}$. On which different types of transparent colored vinyl films were used. The experiments were conducted in the month of October 2018 in the evening between 7.00pm to $8.00 \mathrm{pm}$. By using the all types of color film photos were clicked with the help of Canon EOS 200D 24.2MP Digital SLR Camera. Two experiments were performed. In the first experiment, participants were involved in the field experiment in which each and every two layers of the same film shades of color were used on the headlamp to reduce the glare. Each color headlamp readings were taken out with the help of Lux meter, as well as the graph that has been plotted to get the correct information. In the second experiment the feedback or questioners were asked to the participants regarding the use of different color shades of film to reduce the glare, also any other suggestion or proposal was also taken from them. (Note-No flashlight of the camera was used during clicking the pictures)

\section{Red color film}

When the red color transparent film was used, it was observed that the focus of the headlamp was totally dimmed. Due to which the vision of the people on the vehicle was increased but the focus to see the road was reduced. The high beam, as well as low beam, was not glare free. The intensity of the headlamp on a high beam was measured on day-1 were at a distance of 5m was 209 lux, at distance of $10 \mathrm{~m}$ was $53 \mathrm{lux}$, at distance of $15 \mathrm{~m}$ was $30 \mathrm{lux}$, and a distance of $20 \mathrm{~m}$ was 20 lux. Similarly, as the other four days, values were taken down.

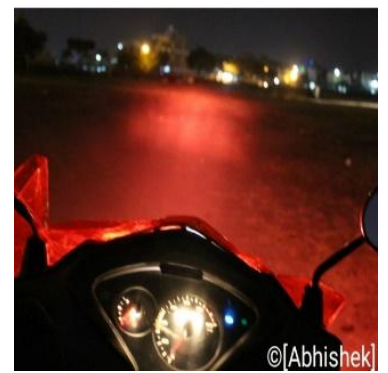

Fig. No. 2 Red Color Film (High beam headlamp)

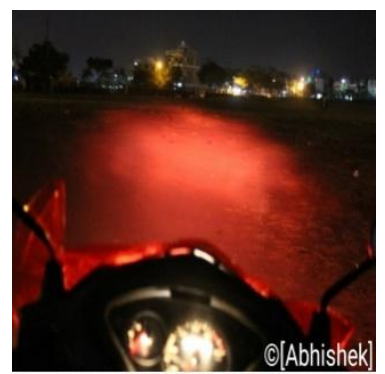

Fig No.3 Red color film (Low beam headlamp)

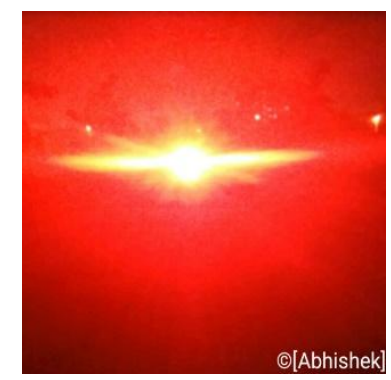

Fig No.4 Front view of headlamp using red color film

\section{Green Color Film}

In the green color film the same problem occurred as in the red color film. Green color film was little success to reduce the strain but as the light was dim the driver was unable to see the road and other things. Because more amount of glare was present from both the beam. Hence other color films were also being tried on the same vehicle. The intensity of the headlamp on a high beam was measured on day- 1 were at a distance of $5 \mathrm{~m}$ was 63 lux, at distance of $10 \mathrm{~m}$ was $37 \mathrm{lux}$, at distance of $15 \mathrm{~m}$ was $22 \mathrm{lux}$, and a distance of $20 \mathrm{~m}$ was 14 lux. Similarly, as the other four days, values were taken down.

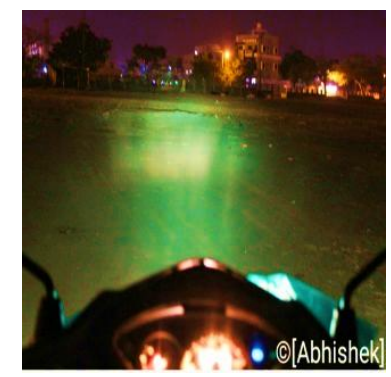

Fig No.5 Green color film (High beam headlamp)

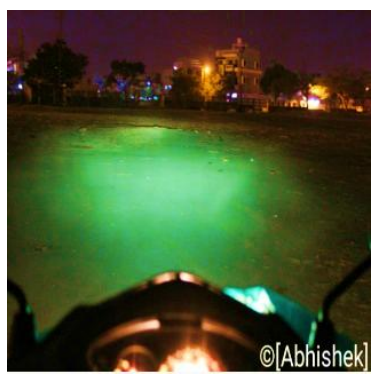

Fig No. 6 Green color film (Low beam headlamp)

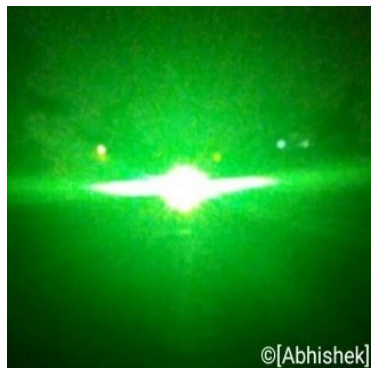

Fig No.7 Front view of headlamp using green color film 


\section{ANTI-GLARE HEADLAMP A SAFE OPTION FOR BETTER VISION TO THE RIDER}

\section{Blue color Film}

As the blue color film was being used on the headlamp the visibility was reduced to see the pedestrians on the road and also it has more glare effect. Even the blue color film didn't make a glare-free headlamp. The intensity of the headlamp on a high beam was measured on day-1 were at a distance of $5 \mathrm{~m}$ was $75 \mathrm{lux}$, at distance of $10 \mathrm{~m}$ was $34 \mathrm{lux}$, at distance of $15 \mathrm{~m}$ was 29 lux, and the distance of $20 \mathrm{~m}$ was 13 lux. Similarly, as Color the other four days, values were taken down.

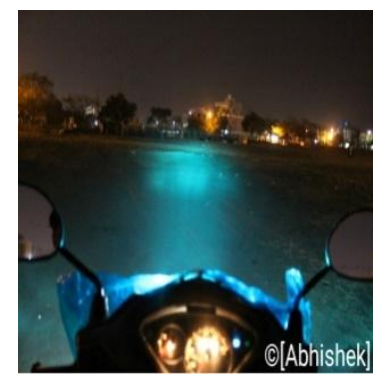

Fig No.8 Blue Color Film

(High beam headlamp)

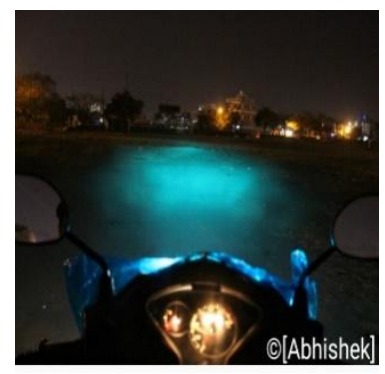

Fig No.9Blue color film (Low beam headlamp)

\section{Yellow Color Film}

Yellow color film was the most effective film than all other types of films, which was giving maximum focus and vision to see on the road. As it was not giving the glare-free effect, we tried the different alternative methods. The intensity of the headlamp on a high beam was measured on day-1 were at a distance of $5 \mathrm{~m}$ was 218 lux, at distance of $10 \mathrm{~m}$ was $186 \mathrm{lux}$, at distance of $15 \mathrm{~m}$ was $54 \mathrm{lux}$, and a distance of $20 \mathrm{~m}$ was 36 lux. Similarly, as the other four days, values were taken down.

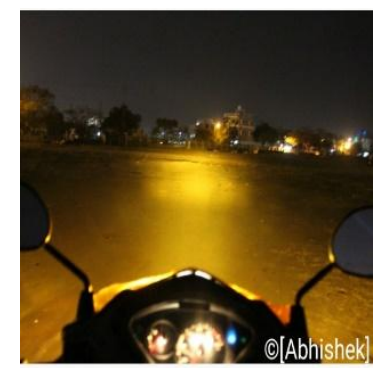

Fig No.11 Yellow color film (High beam headlamp)

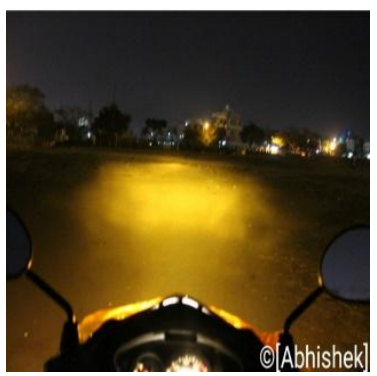

Fig No.12 Yellow color film (Low beam headlamp)

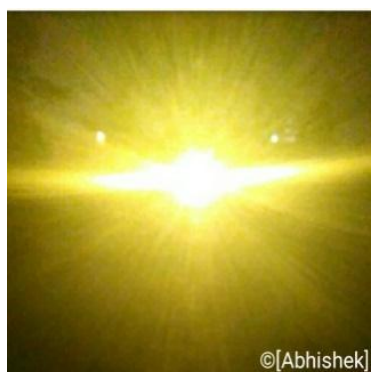

Fig No.13 Front view of headlamp using yellow color film

\section{Yellow and Green Color Film}

When the yellow and green color film were used it gave sufficient visibility to see the road, pedestrian and other things and also it gave a glare-free effect which was a successful experiment for us. The mixture of the yellow and green film was successful to reduce the glare on high beam as well as on low beam headlamp. The intensity of the headlamp on a high beam was measured on day- 1 were at a distance of $5 \mathrm{~m}$ was 94 lux, at distance of $10 \mathrm{~m}$ was $56 \mathrm{lux}$, at distance of $15 \mathrm{~m}$ was 29 lux, and the distance of $20 \mathrm{~m}$ was 23 lux. Similarly, as the other four days, values were taken down.

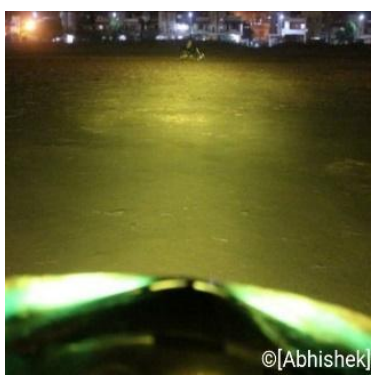

Fig No.14 Yellow and green color film (High beam headlamp)

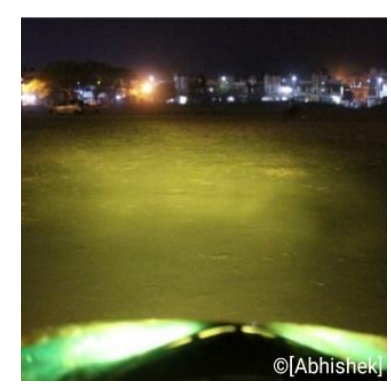

Fig No.15 Yellow and green color film (Low beam headlamp) 


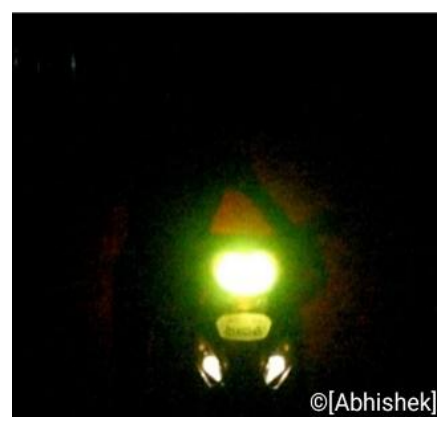

Fig No.16 Front view of headlamp using yellow and green color film

\section{RESULTS AND DISCUSSIONS}

The present study provides strong evidence that a mixture of the yellow and green color transparent colored vinyl film is most suitable for a glare-free headlamp. We have demonstrated the flexibility of headlight for numerous tasks, allowing the motorist to use a high beam without glaring any other motorist on the road and allowing better illumination of road lanes any other things on road. Participants drove at night in actual traffic along a track. Intensity is being measured of each and every colored headlight, as per the outputs of the readings the graph has been plotted. The tables and graphs of five days show that the considerable drop in the intensity but there is low glare in yellow and green color mixture. The tables and graph of five days with the values has been plotted below.

Day-1

Table No.1:- Measurement of Intensity using Different Types of Films on Halogen Bulb Headlamp at Various Distances

\begin{tabular}{|c|c|c|c|c|c|}
\hline $\begin{array}{c}\text { Distance } \\
(\mathbf{m})\end{array}$ & \multicolumn{5}{|c|}{ Intensity of Colors in lux } \\
\hline & Red & Yellow & Green & Blue & $\begin{array}{c}\text { Yellow and } \\
\text { Green }\end{array}$ \\
\hline 5 & 209 & 218 & 63 & 75 & 94 \\
\hline 10 & 53 & 186 & 37 & 34 & 56 \\
\hline 15 & 30 & 54 & 22 & 29 & 29 \\
\hline 20 & 20 & 36 & 14 & 13 & 23 \\
\hline
\end{tabular}

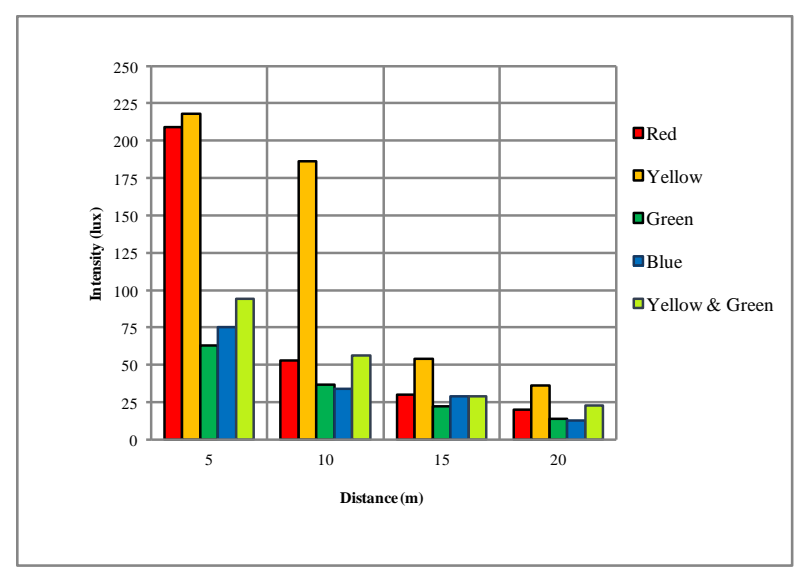

Fig No.17 Distance Vs Intensity
Day-2

Table No.2:- Measurement of Intensity using Different Types of Films on Halogen Bulb Headlamp at Various Distances

\begin{tabular}{|c|c|c|c|c|c|}
\hline $\begin{array}{c}\text { Distance } \\
(\mathbf{m})\end{array}$ & \multicolumn{5}{|c|}{ Intensity of Colors in lux } \\
\hline & Red & Yellow & Green & Blue & $\begin{array}{c}\text { Yellow } \\
\text { and Green }\end{array}$ \\
\hline 5 & 208 & 216 & 63 & 71 & 94 \\
\hline 10 & 53 & 184 & 37 & 33 & 55 \\
\hline 15 & 29 & 57 & 24 & 30 & 29 \\
\hline 20 & 18 & 36 & 16 & 12 & 24 \\
\hline
\end{tabular}

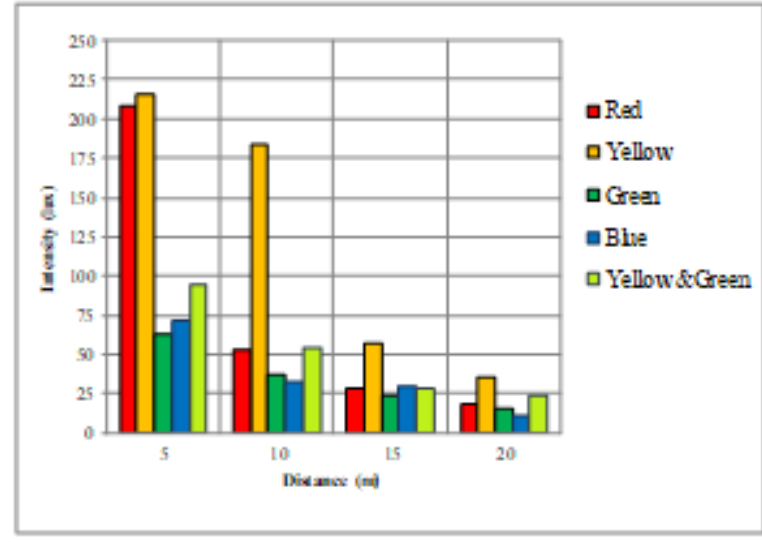

Fig No.18 - Distance Vs Intensity

Day-3

Table No.3:- Measurement of Intensity using Different Types of Films on Halogen Bulb Headlamp at Various Distances

\begin{tabular}{|c|c|c|c|c|c|}
\hline $\begin{array}{c}\text { Distance } \\
(\mathbf{m})\end{array}$ & \multicolumn{5}{|c|}{$\begin{array}{c}\text { Intensity of Colors } \\
\text { in lux }\end{array}$} \\
\hline & Red & Yellow & Green & Blue & $\begin{array}{c}\text { Yellow and } \\
\text { Green }\end{array}$ \\
\hline 5 & 209 & 217 & 65 & 72 & 96 \\
\hline 10 & 55 & 185 & 36 & 35 & 55 \\
\hline 15 & 28 & 55 & 22 & 29 & 29 \\
\hline 20 & 19 & 35 & 14 & 13 & 21 \\
\hline
\end{tabular}

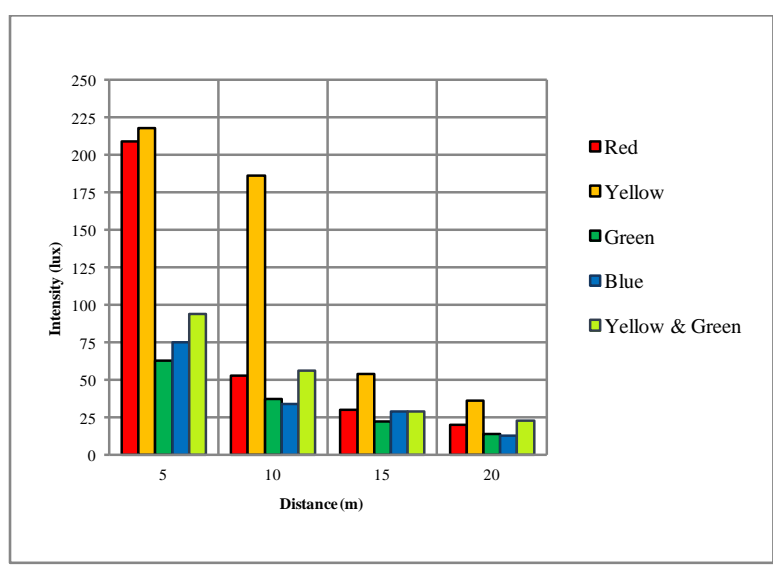

Fig No. 19 Distance Vs Intensity 
Day-4

Table No.4:- Measurement of Intensity using Different Types of Films on Halogen Bulb Headlamp at Various Distances

\begin{tabular}{|c|c|c|c|c|c|}
\hline $\begin{array}{c}\text { Distance } \\
(\mathbf{m})\end{array}$ & \multicolumn{5}{|c|}{ Intensity of Colors in lux } \\
\hline & Red & Yellow & Green & Blue & $\begin{array}{c}\text { Yellow and } \\
\text { Green }\end{array}$ \\
\hline 5 & 209 & 218 & 63 & 75 & 94 \\
\hline 10 & 51 & 186 & 35 & 37 & 56 \\
\hline 15 & 30 & 53 & 22 & 32 & 32 \\
\hline 20 & 20 & 36 & 14 & 13 & 25 \\
\hline
\end{tabular}

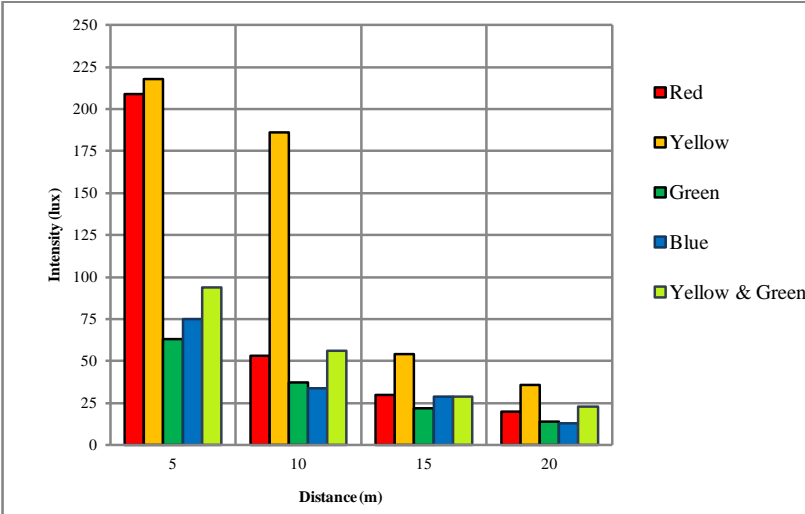

Fig No. 20 - Distance Vs Intensity

Day-5

Table No.5:- Measurement of Intensity using Different Types of Films on Halogen Bulb Headlamp at Various Distances

\begin{tabular}{|c|c|c|c|c|c|}
\hline $\begin{array}{c}\text { Distance } \\
(\mathbf{m})\end{array}$ & \multicolumn{5}{|c|}{ Intensity of Colors in lux } \\
\hline & Red & Yellow & Green & Blue & $\begin{array}{c}\text { Yellow and } \\
\text { Green }\end{array}$ \\
\hline 5 & 211 & 220 & 63 & 77 & 94 \\
\hline 10 & 53 & 186 & 39 & 34 & 59 \\
\hline 15 & 32 & 53 & 22 & 30 & 30 \\
\hline 20 & 21 & 36 & 14 & 13 & 25 \\
\hline
\end{tabular}

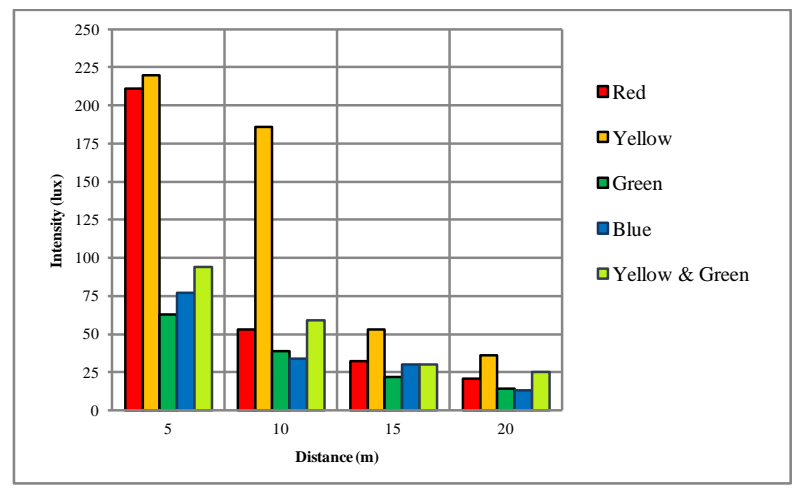

Fig No.21 Distance Vs Intensity

The average of all the five readings were depicted in the table no 6 along with the fig no. 23 .
Table No.6:- Measurement of Intensity using Different Types of Films on Halogen Bulb Headlamp at Various Distances

\begin{tabular}{|c|c|c|c|c|c|}
\hline Distance & \multicolumn{5}{|c|}{ Colors } \\
\hline (m) & Red & Yellow & Green & Blue & $\begin{array}{c}\text { Yellow } \\
\text { and } \\
\text { Green }\end{array}$ \\
\hline 5 & 210 & 220 & 64 & 75 & 97 \\
\hline 10 & 54 & 186 & 38 & 36 & 57 \\
\hline 15 & 30 & 56 & 22 & 30 & 30 \\
\hline 20 & 20 & 37 & 15 & 13 & 23 \\
\hline
\end{tabular}

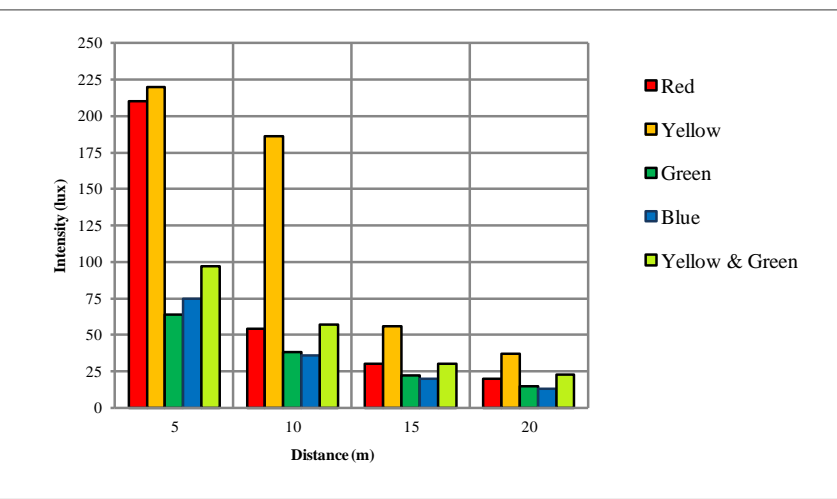

Fig No. 22 Distance Vs Intensity

The above average graph shows that the yellow and red color film have more intensity as compared to other color films. Whereas the mixture of the yellow and green color film shows a minimum intensity than the red and yellow color film.

\subsection{Spectrometer Readings}

An automotive headlight with a halogen bulb arranged in a dark room with the spectrometer. First, the headlight has been seen under the spectrometer without the filters. The outcome of the spectrum without filters shown in Fig No.23, which shows that the headlight without filters having the unnecessary high intensity which is proportional to the more glare. At the second time, the headlight with filters has been seen under the spectrometer the results shown in the Fig No.24 shows that the unwanted or unnecessary intensity has been reduced through the spectrum and also the glare also has been reduced.

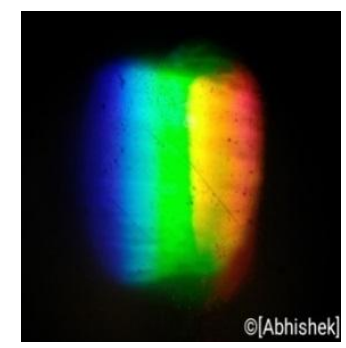

Fig No.23 Halogen bulb headlamp without any film under spectrometer 


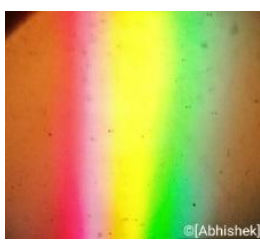

Fig No. 24 Halogen bulb headlamp with mixture of yellow and green color film under spectrometer

The experiments were conducted on the field for five days and the feedback of 150 people was taken during these five days. The questionaries' forms regarding the Anti-Glare headlamp were filled by these 150 peoples. The feedback is depicted in the table no 7 below.

\subsection{Anti-Glare Headlamp Feedback Form}

Table No.7:- Visual Feedback from the Drivers

\begin{tabular}{|c|c|c|c|}
\hline \multirow{2}{*}{$\begin{array}{l}\text { Sr. } \\
\text { No }\end{array}$} & \multirow{2}{*}{ Questionaries' } & \multicolumn{2}{|c|}{ Remarks } \\
\hline & & YES & NO \\
\hline 1 & Do you experience poor night vision? & $38 \%$ & $62 \%$ \\
\hline 2 & $\begin{array}{l}\text { Are you bothered of the glare of } \\
\text { oncoming vehicles? }\end{array}$ & $80 \%$ & $20 \%$ \\
\hline 3 & $\begin{array}{l}\text { Does anti-glare the headlamp help you } \\
\text { to avoid blindness by headlamp of } \\
\text { oncoming vehicles? }\end{array}$ & $87 \%$ & $13 \%$ \\
\hline 4 & $\begin{array}{l}\text { During the actual meeting with the } \\
\text { oncoming vehicles, was there any } \\
\text { difference in visibility with using anti- } \\
\text { glare headlamp? }\end{array}$ & $82 \%$ & $18 \%$ \\
\hline 5 & $\begin{array}{l}\text { Are you feeling safe while driving } \\
\text { with using anti-glare headlamp? }\end{array}$ & $87 \%$ & $13 \%$ \\
\hline 6 & $\begin{array}{l}\text { Does anti-glare headlamp reduce } \\
\text { visibility? }\end{array}$ & $67 \%$ & $33 \%$ \\
\hline 7 & $\begin{array}{l}\text { Will you prefer the anti-glare } \\
\text { headlamp at night? }\end{array}$ & $80 \%$ & $20 \%$ \\
\hline 8 & Will it be helpful to avoid accidents? & $85 \%$ & $15 \%$ \\
\hline 9 & Is anti-glare headlamp cost efficient? & $100 \%$ & 0 \\
\hline 10 & $\begin{array}{l}\text { Should the Government of India be } \\
\text { made halogen headlamp mandatory } \\
\text { with a mixture of yellow and green } \\
\text { color transparent vinyl film? }\end{array}$ & $73 \%$ & $27 \%$ \\
\hline
\end{tabular}

\section{CONCLUSION}

Headlamp should able to adapt the critical driving situation at night due to high glared headlamp and also improve its visibility. It should be capable of performing many different tasks to help motorists in multiple road environments. In the present study it was concluded that the yellow color film gives sufficient visibility to the motorist but as it does not give a glare-free effect, therefore, a green color film is added in it. The mixture of the yellow and green color transparent vinyl film is the most effective method for a glare-free halogen bulb headlamp. As the average values of the film were 97 lux at $5 \mathrm{~m}$ distance, 57lux at $10 \mathrm{~m}$ distance, 30 lux at the $15 \mathrm{~m}$ distance and 23 lux at the $20 \mathrm{~m}$ distance which shows that the glare of halogen bulb has been reduced. Some other improvements can be done in resurfacing the headlight using a transparent vinyl color film which will be beneficial to everyone.

\section{REFERENCES}

1. John D Bullough, Kate Sweater Hikcox, N Narendran, "A Method for Estimating Discomfort Glare from Exterior Lightning Systems", Lightning Research Center, Rensselaer Polytechnic Institute, USA, Volume 9, pp. 1-4, April 2011.

2. J. D. Bullough, N. P. Skinner, R. M. Pysar, L. C. Radetsky, A. M. Smith and M. S. Rea, "Nighttime Glare and Driving." National Highway Traffic Safety Administration, Washington, DC, Report No.DOT HS 811 043, September 2008.

3. Robert Tamburo, Eriko Nurvitadhi, Abhishek Chugh, Mei Chen, Antony Rowe, Tikeo Kanade, Srinivasa G Narasimhan, "Programmable Automotive Headlights", Computer VisionECCV 2014 Lecture Notes in Computer Science, Volume 8692, Springer, Cham, pp.750-765, January 2014.

4. Oliver Wang, Martin Fuchs, Christian Fuchs, James Davis, Hans-Peter Seidel, Hendrik P. A. Lensch, "A context-aware light source”, Computational Photography (ICCP), 2010 IEEE International Conference, IEEE, pp1-8, March 2010.

5. John Van Derlofske, John D. Bullough, Peping DEE, Jie Chen, Yukio Akashi. "Headlamp parameters and Glare",SAE Technical paper, pp 1-11, March 2004.

6. John D Bullough and John Van Derlofske, "Headlamp Illumination and Glare: An Approach to Predicting Peripheral Visibility", SAE Technical Paper, pp 22-34, March 2004.

7. Yukio Akashi and Mark Rea, "The effect of oncoming headlight glare on peripheral detection under a mesopic light level", The National Academies of Sciences, Engineering and Medicine, Washington, DC, Reference Book, pp. 9-22, January 2001.

8. Balk, Stacy, Tyrrell, Richard, "The accuracy of driver judgment of the effects of headlight glare: are we really blinded by the light?", International Conference at Olympic Valley- Lake Tahoe CA, pp. 510-517, October 2017.

9. "Nighttime Glare and Driving Performance, Report to Congress", (2007) National Highway Traffic Safety Administration, pp 25-39, February 2007.

10. Riccardo Bianchin, "Light sources for exhibition design part1", Inexhibit photos, Inexhibit, Bianchini and Lusiardi associated architects, pp 32-45, September 2018.

11. International Light Technology "Tungsten halogen lamps and Gas filled lamps", Inexhibit photos, Inexhibit, Bianchini and Lusiardi associated architects, pp 21-33, 2018.

12. Roger H. Hemion, "The Effect of Headlight Glare on Vehicle Control and Detection of Highway Vision Targets", Report No.AR-640, 01, 1, pp 45-74, May 1968.

13. Stephanie A Whetsel Borzendowski, Ashley A. Stafford Sewall, Patrick J. Rosopa, Richard A. Tyrrell. "Drivers' judgments of the effect of headlight glare on their ability to see pedestrians at night", National Safety Council and Elsevier Ltd, Volume 53, pp. 31-37, June 2015

14. John D Bullough, Nicholas P. Skinner, Yukio Akashi, and John Van Derlofske, "Investigation of Safety-Based Advanced Forward-Lighting Concepts to Reduce Glare", Lighting Research Center, Rensselaer Polytechnic Institute, USA, Report No. DOT HS 811 033, 01, pp43-56, September 2007

15. Van Derlofske, J., Chen, J., Bullough, J., and Akashi, Y. "Headlight Glare Exposure and Recovery," SAE 2005 World Congress \& Exhibition, Technical Paper 2005-01-1573, April 2005 . 